\title{
Recovery from severe mental illness
}

\author{
Rob Whitley PhD, Victoria Palmer PhD, Jane Gunn MBBS PhD \\ CMAJ Podcast: author interview at soundcloud.com/cmajpodcasts/mental-illness-recovery
}

$\mathrm{T}$ he concept of mental health "recovery" is based on evidence that people with severe mental illnesses can live autonomous, contributing and satisfying lives in the community, even in the presence of persisting symptoms. Jurisdictions around the world, including Canada, are calling for mental health services to become "recovery-oriented." We present the concept of mental health "recovery" and discuss ways in which a recovery orientation can be integrated into everyday clinical work.

"Severe mental illness" is an umbrella term used by researchers to categorize the most serious mental disorders that share basic characteristics, including intense symptom severity and severe functional impairment when the condition goes untreated. In this article, we refer to people with a diagnosis of one of four discrete mental illnesses - schizophrenia, bipolar disorder, major depressive disorder and schizoaffective disorder - as having severe mental illness. ${ }^{1}$ Others, such as psychiatric epidemiologists, may include substance use disorder and personality disorder in their definition. ${ }^{2}$ The United States National Comorbidity Survey Replication defined severe mental illness broadly, finding 12 -month prevalence rates of $5.8 \% .^{3}$ Studies with narrower definitions find lower prevalence. ${ }^{2}$

For much of the 20th century, severe mental illness was considered chronic and deteriorating, requiring institutional tertiary care or highintensity secondary care. ${ }^{1}$ This approach changed in the 1960s with the advent of antipsychotic drugs and subsequent deinstitutionalization, which gave new hope to patients with severe mental illness who were discharged into the community. However, research in the period after this shift found that people with severe mental illness often ended up without housing, jobs or social supports, leaving them vulnerable and stigmatized. ${ }^{4}$ These problems remain disproportionately prevalent among people with severe mental illness today. ${ }^{1}$

The concept of mental health recovery has emerged with mounting prominence in response to these ongoing injustices and to the perceived weaknesses in standard psychiatric care, which is considered to overemphasize the biological to the detriment of the psychosocial. Many definitions of recovery exist, but shared across these definitions is an emphasis on recovery as an individual process (or journey) involving much more than symptom remission. Instead, recovery involves development in life domains considered subjectively important to the person, commonly related to progress in normative activities such as education, employment, housing and social relationships. ${ }^{1}$ Autonomy and choice in mental health care are considered central to the concept of recovery. ${ }^{5}$

The concept of recovery is supported by scientific evidence. Epidemiologic research has consistently shown that severe mental illness is not always a lifelong or even a chronic condition; substantial numbers of people with severe mental illness have a reduction of both symptoms and associated secondary impairments over time. ${ }^{6}$ Health services research has shown strong evidence for psychosocial interventions (e.g., supported employment) that promote recovery by helping people achieve autonomy and life progress. ${ }^{5}$ Cross-national comparisons have shown that people with severe mental illness have better outcomes in places where they remain integrated within families, workplaces and communities. ${ }^{7}$ Numerous autobiographic and qualitative accounts have shown the reality of recovery: people can define and achieve important life goals despite ongoing symptoms. ${ }^{1}$
Competing interests: Rob Whitley is a member of the Mental Health Commission of Canada's Opening Minds initiative principal investigators group. Jane Gunn reports grant funding from the National Health and Medical Research Council (NHMRC); she has received personal fees as chair of the board of the Northern Melbourne Medicare Local, chair of NPS MedicineWise

MedicineInsight, and member of the NHMRC

Research Committee and other NHMRC panels.

This article has been peer reviewed.

Correspondence to: Rob Whitley, robert.whitley @mcgill.ca

CMAJ 2015. DOI:10.1503 /cmaj.141558 
National strategies and mental health commissions in Australia, New Zealand, Canada and the US have officially supported the adoption of a recovery approach. Former Canadian Senator Michael Kirby published a seminal paper in the $C M A J^{8}$ in support of the autonomy-promoting community integration notions of recovery, noting that people with serious mental illness

... should be helped to live their lives to the fullest extent possible within the limitations of their illness. ... [R]ecovery requires a departure from traditional service delivery models and it requires working with patients, not seeking to solve their problems for them or to simply reduce their symptoms.

This attitude has been officially endorsed by the Mental Health Commission of Canada, a federally funded commission with a 10 -year mandate (2007-2017). The commission has been tasked with various national initiatives, such as developing Canada's first national mental health strategy, which was released in May 2012. ${ }^{9}$ The strategy states that a key aim of mental health services must be to "foster recovery and well-being for people of all ages living with mental health problems and illnesses, and uphold their rights."

These ideas are often termed "the recovery paradigm," and the growing number of recovery advocates and activists are collectively known as "the recovery movement." The enthusiasm for the concept of recovery is shared across diverse sectors, including patient advocates, clinicians, researchers and governments, which has resulted in a general consensus that the adoption of a recovery orientation throughout health services is desirable. ${ }^{9}$

Adoption involves several factors related to everyday clinical work, including adopting a positive, optimistic and hopeful attitude when working with people with severe mental illness, eliciting information on subjective life goals and working with patients to help achieve those goals,${ }^{5}$ and enacting shared decision-making in the clinical encounter, especially in medication management, ${ }^{1}$ so that patients have choice and autonomy regarding intervention options.

Psychosocial interventions, such as supported employment and supportive housing, are unevenly available across Canada; they require systemlevel change and investment. ${ }^{89}$ Moreover, new approaches (e.g., shared decision-making) involve skills that may require additional training and extra time spent in consultations. ${ }^{1,5}$

The practice of psychiatry was traditionally based on the biopsychosocial model, which emphasized a holistic approach to healing. ${ }^{10}$ However, convincing arguments have been made as to psychiatry's recent switch to a de facto "bio-bio-bio" model. The recovery paradigm contains much that is new, such as the emphasis on patient choice, autonomy and shared decisionmaking in the clinic. However, it also contains much that is old and noble about psychiatry, particularly the emphasis on holistic care addressing the psychosocial as much as the biological.

\section{References}

1. Drake RE, Whitley R. Recovery and severe mental illness: description and analysis. Can J Psychiatry 2014;59:236-42.

2. Ruggeri M, Leese M, Thornicroft G, et al. Definition and prevalence of severe and persistent mental illness. Br J Psychiatry 2000; 177:149-55.

3. Kessler RC, Chiu WT, Demler O, et al. Prevalence, severity and comorbidity of 12-month DSM-IV disorders in the national comorbidity survey replication [published erratum in Arch Gen Psychiatry 2005;62:709.] Arch Gen Psychiatry 2005; 62:617-27.

4. Estroff SE. Making it crazy: an ethnography of psychiatric clients in an American community. Berkeley (CA): University of California Press; 1981.

5. Slade M, Amering M, Farkas M, et al. Uses and abuses of recovery: implementing recovery-oriented practices in mental health systems. World Psychiatry 2014;13:12-20.

6. Harding CM, Zubin J, Strauss JS. Chronicity in schizophrenia: revisited. Br J Psychiatry Suppl 1992;18:27-37.

7. Leff J, Sartorius N, Jablensky A, et al. The International Pilot Study of Schizophrenia: five-year follow-up findings. Psychol Med 1992;22:131.

8. Kirby M. Mental health in Canada: out of the shadows forever. CMAJ 2008;178:1320-2

9. Changing directions changing lives: the mental health strategy for Canada. Calgary: Mental Health Commission of Canada; 2012.

10. Shorter E. A history of psychiatry: from the era of the asylum to the age of Prozac. New York: John Wiley \& Sons; 1997.

Affiliations: Department of Psychiatry (Whitley), Douglas Mental Health University Institute, McGill University, Montréal, Que.; Department of General Practice (Palmer, Gunn), the University of Melbourne, Melbourne, Australia

Contributors: All of the authors contributed substantially to the writing and revising of the manuscript. All of the authors approved the final version of the article and agree to act as guarantors of the work. 